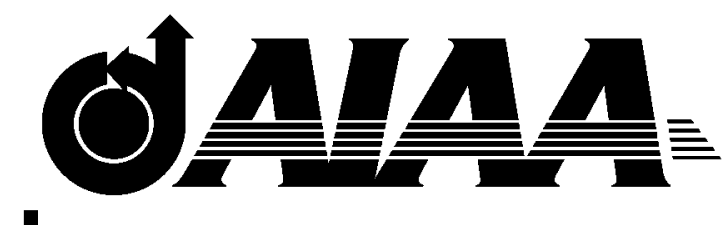

\title{
AIAA 2002-2496 \\ Active Control of Turbulent Boundary Layer Induced Sound Radiation from Multiple Aircraft Panels
}

Gary P. Gibbs, Randolph H. Cabell

NASA Langley Research Center, Hampton, VA 23681

\section{8th AIAA/CEAS Aeroacoustics Conference June 16-18, 2002/Breckenridge, CO}




\title{
Active Control of Turbulent Boundary Layer Induced Sound Radiation from Multiple Aircraft Panels
}

\author{
Gary P. Gibbs*, Randolph H. Cabell* \\ NASA Langley Research Center, Hampton, VA 23681
}

\begin{abstract}
The objective of this work is to experimentally investigate active structural acoustic control of turbulent boundary layer (TBL) induced sound radiation from multiple panels on an aircraft sidewall. One possible approach for controlling sound radiation from multiple panels is a multi-input/multi-output scheme which considers dynamic coupling between the panels. Unfortunately, this is difficult for more than a few panels, and is impractical for a typical aircraft which contains several hundred such panels. An alternative is to implement a large number of independent control systems. Results from the current work demonstrate the feasibility of reducing broadband radiation from multiple panels utilizing a single-input/single-output (SISO) controller per bay, and is the first known demonstration of active control of TBL induced sound radiation on more than two bays simultaneously. The paper compares sound reduction for fully coupled control of six panels versus independent control on each panel. An online adaptive control scheme for independent control is also demonstrated. This scheme will adjust for slow time varying dynamic systems such as fuselage response changes due to aircraft pressurization, etc.
\end{abstract}

\section{Introduction}

Reduction of interior noise in commercial and general aviation aircraft has been the subject of research for many years. Considerable progress has been made in active control of tonal noise such as propeller blade passage noise, and several noise control systems are in use on commuter aircraft. In contrast, noise in high subsonic and supersonic aircraft is typically broadband and is dominated by turbulent boundary layer (TBL) noise and jet noise. TBL noise is essentially spatially and temporally incoherent. This severely limits the use of feedforward control techniques which have been successfully applied to tonal noise.

Active control of TBL induced radiated noise has been the subject of several analytical studies, but relatively few experiments. The analytical studies include work by Thomas and Nelson, ${ }^{1}$ Heatwole et al., ${ }^{2}$ Maury et al., ${ }^{3}$ and Augereau. ${ }^{4}$ Most of the experimental work has been focused on controlling sound radiated from rectangular plates, ${ }^{5}$ since a plate resembles a single panel in the sidewall of an aircraft fuselage. Gibbs et al. demonstrated active control of turbulent boundary layer induced sound radiation from aircraft panels using generalized predictive control and radiation filters. ${ }^{6}$ In their work, reductions in the radiated sound power on the order of $10-20 \mathrm{~dB}$ at resonance and $5-10$ dB integrated over a bandwidth of $150-800 \mathrm{~Hz}$ were achieved. The control system used 3 actuators and

\footnotetext{
* Structural Acoustics Branch

Copyright (c) 2002 by the American Institute of Aeronautics and Astronautics, Inc. No copyright is asserted in the United States under Title 17, U.S. Code. The U.S. Government has a royaltyfree license to exercise all rights under the copyright claimed herein for Governmental Purposes. All other rights are reserved by the copyright owner.
}

15 sensors (to predict radiation) per panel bay. Later work by Gibbs et al. demonstrated that control system complexity could be significantly reduced ${ }^{7}$ resulting in a single actuator and 4 sensors per bay. Augereau analytically developed a feedback control system model of a panel excited by a turbulent boundary layer. ${ }^{4}$ His work demonstrated exceptional analytical agreement with the work previously presented by Gibbs ${ }^{7,6}$ and provides a valuable design and analysis tool.

The present paper describes experiments on simultaneous active control of six panels in a model of an aircraft sidewall. Two different feedback control schemes will be presented: a single controller which provides sensing and control of all of the bays together, and a control scheme where each bay is independently controlled. For the independently controlled case, the performance of static gain controllers is compared with an online adaptive control scheme.

\section{Test Configuration}

A test panel was constructed as shown in Figure 1 as a flat embodiment of an aircraft fuselage sidewall. The structure is made of aluminum and consists of six bays separated from one another by aluminum frames and stringers. Each bay had dimensions of 20 " x 10 " with skin thickness of $0.063 "$. In-plane tension was applied to the panel in the cross flow direction to simulate the hoop stress in a pressurized aircraft flying at 40,000 feet. The panel was mounted in the sidewall of a wind tunnel where it was subjected to TBL excitation due to the presence of flow. This configuration has been used previously in several active control tests ${ }^{7}$ and is similar to that utilized by Gibbs et al. ${ }^{6}$ 


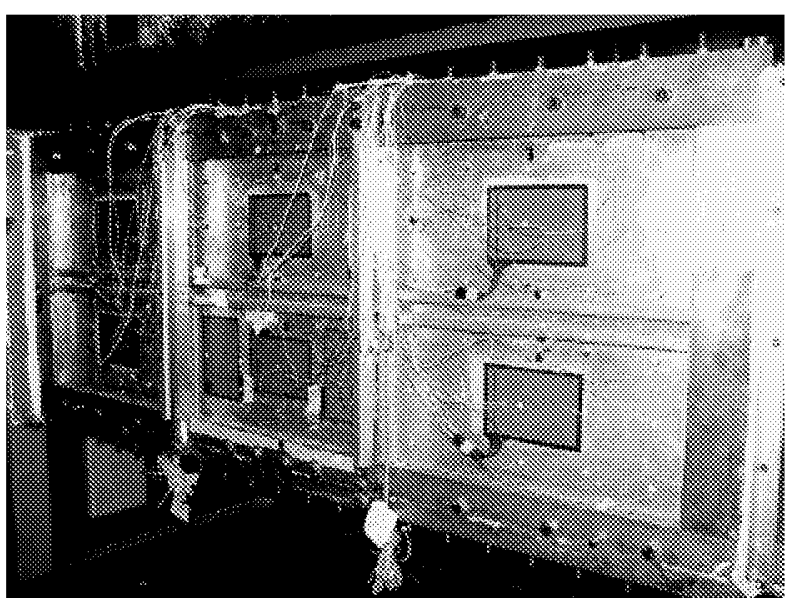

Fig. 1 Photograph of Test Panel

For control actuation and sensing, each bay was configured with one center-mounted piezoceramic actuator (PZT - 5A, 6" x 4" x 0.015") and 15 accelerometers (Endevco 2250A). The summed output of a diamond pattern of four accelerometers was previously found to provide a reasonable estimate of the sound radiation for feedback control, ${ }^{7}$ and this arrangement was used as the controller performance function for these experiments. The radiated sound power was estimated from the 15 accelerometers mounted on each bay using a discrete implementation of Rayleigh's Integral. ${ }^{8}$

A floating point digital signal processor (DSP) was used to implement feedback control. The sample rate of the controllers was $3 \mathrm{kHz}$. Four-pole filters with corner frequencies of $1 \mathrm{kHz}$ were used for anti-aliasing and smoothing on all input and output signals.

\section{Control Topology}

A generalized predictive control (GPC) ${ }^{9}$ scheme was used to compute the feedback gains in these experiments. GPC is a model predictive control scheme, and is a special case of more well-known linear quadratic control methods. ${ }^{10}$ The basic concept behind model predictive controllers is to use a separately identified plant model to predict the plant response a number of time steps into the future due to a sequence of future control inputs and system outputs. The future control inputs are then optimized to produce a desired plant response. ${ }^{11}$ Only the first computed control input is applied, however, and the process is then repeated at the next time step to compute a new control input. It is possible to incorporate online system identification with GPC control design, to produce a fully adaptive controller.

The control inputs are computed to optimize a quadratic cost function. Assume the $(m \times 1)$ vector $\mathbf{y}(k)$ denote a vector of responses of $m$ sensors at time $k$, and the $(r \times 1)$ vector $\mathbf{u}(k)$ denote a vector of inputs to $r$ control actuators. The GPC control cost function is written

$$
J=\sum_{j=q}^{p-1}\|\mathbf{y}(k+j)\|^{2}+\lambda \sum_{j=0}^{p-1}\|\mathbf{u}(k+j)\|^{2}
$$

where $k$ denotes the current time index. This cost depends on sensor responses from time $q$ to $(p-1)$ steps into the future, and control inputs from the current time to $(p-1)$ steps into the future. The control penalty, $\lambda$, in the cost function determines the importance of the control inputs relative to the system responses. The parameter $p$ specifies the performance horizon, and is usually chosen to be several times longer than the rise time of the plant in order to ensure a stable feedback controller. ${ }^{12}$ If the performance horizon starts at the current time step, $(q=0)$, then as $p \rightarrow \infty$, the resulting controller approaches the steady-state linear quadratic regulator. ${ }^{12}$ A more detailed description of the controller configuration used in this experiment can be found in the references. ${ }^{7,6}$

The 6 bays and actuators are like numbered as shown in Figure 2. A schematic of a SISO GPC controller for TBL induced sound radiation is also shown in Figure 2 operating on bay 4 for example. The 4 accelerometer responses are summed to produce an estimate of the first radiation mode of the structure. This topology was previously shown to provide an accurate estimate of the radiated sound power from this structure. ${ }^{7}$ The summed accelerometer responses are fed to the GPC controller which creates the desired actuator voltage to minimize the radiated sound power. In the 6-bay MIMO control system, the summed accelerometer signals from each bay produce a total of 6 sensor signals. These signals are passed to a fully coupled 6 input/ 6 output GPC controller which then generates control voltages for the 6 actuators.

The GPC controller requires a model of the transfer function from actuator input to sensor response. This transfer function could have multiple inputs and multiple outputs for the MIMO case. The models were computed from measured input-output data, where the actuator or actuators were driven with a broadband random signal, and the corresponding sensor responses were recorded. For the MIMO control case, the state space model had 6 inputs, 6 outputs, and 240 states. For the SISO case, a 100th order polynomial model was computed, since a polynomial topology is more efficient for SISO controllers. Note that the SISO controllers did not take into account any coupling between neighboring bays on the test structure. This coupling can have a significant impact on the stability and performance of the control system.

An adaptive SISO control system was also studied to evaluate its effectiveness at producing stable controllers in spite of coupling between bays. This adaptive approach was similar to loop closure methods used in flight control. ${ }^{13} \mathrm{~A}$ schematic of the adaptive control approach, as used on two coupled bays, is shown 


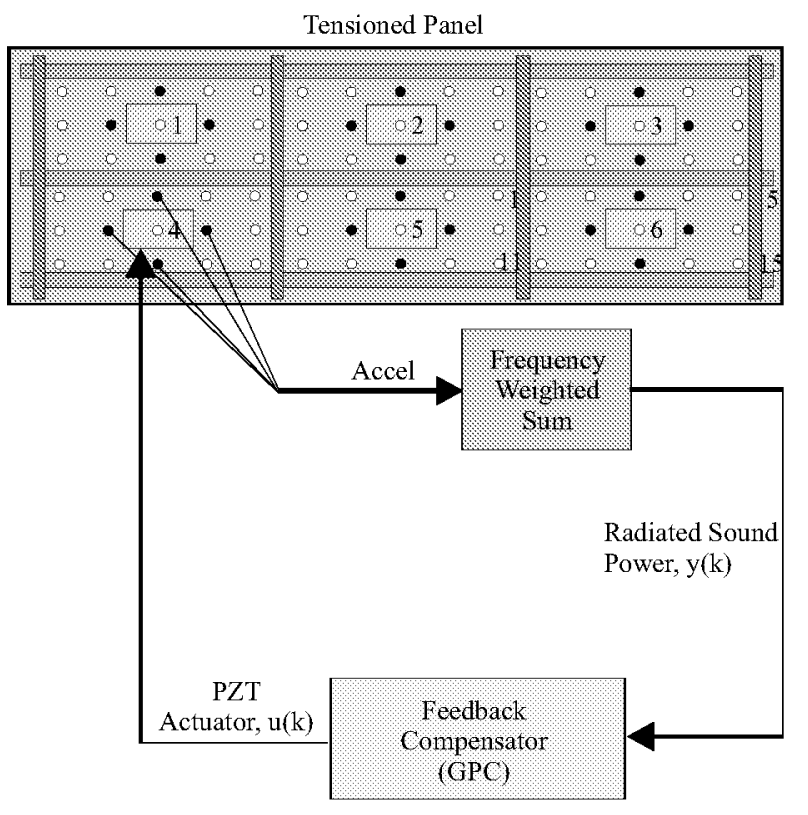

Fig. 2 Schematic of the Generalized Predictive Controller

in Figure 3. In this scheme system ID and closed loop control is applied on each bay sequentially. Initially, system identification is done on bay 1 , then an optimal controller is designed with a very conservative control effort penalty. The controller is then implemented on bay 1 . The system identification and control design procedure is then applied to bay 2, while the controller on bay 1 is running in closed loop mode. The controller is then implemented on bay 2 . The entire process is repeated on both bays, with the effort penalty constant. If the controllers are both stable, the effort penalty is reduced, and the entire process repeated. For the experiments conducted here, the sequence of system id and control design was repeated until the best noise reduction performance was obtained.

\section{Experimental Results}

The sound reduction performance of different feedback control schemes were compared at a tunnel flow speed of Mach 0.125. First, all 6 bays were controlled with a fully coupled MIMO feedback controller. These results were then compared with the performance of six SISO controllers, one on each bay. Significant coupling was observed between neighboring panels on the structure, so further experiments were conducted on neighboring bays in the cross-flow (bays 1 and 4) and flow directions (bays 1 and 2). The performance of the adaptive control scheme was studied on these twopanel cases as well.

\section{Six Bay Control}

The total radiated sound power reduction results for the 6-bay MIMO control configuration are shown in Figure 4. The uncontrolled panel response was dominated by the resonance at $\sim 180 \mathrm{~Hz}$; this was previously

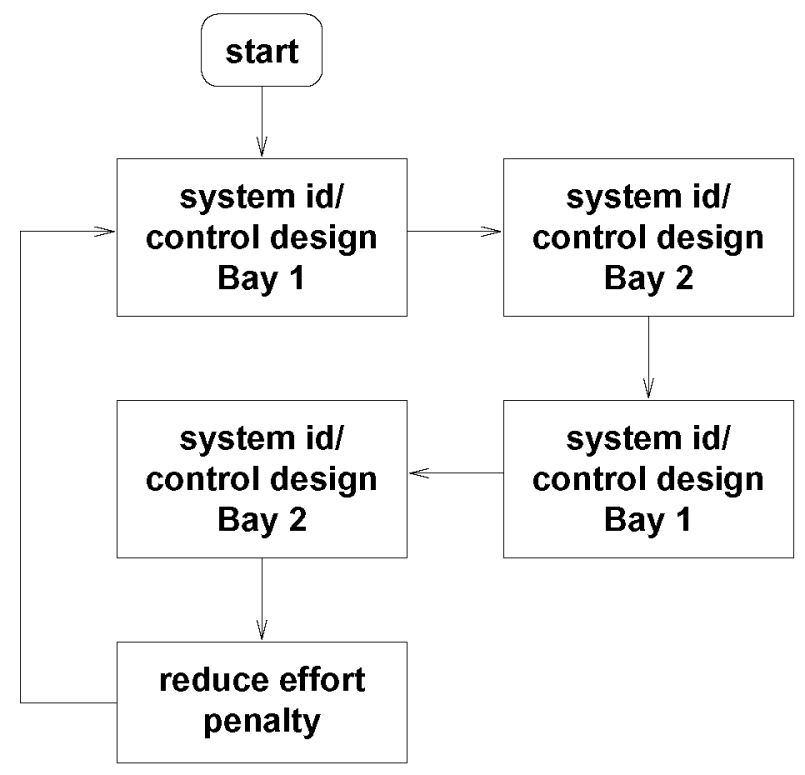

Fig. 3 Adaptive Control Block Diagram

determined to be a $(3,1)$ mode of the whole 6 bay panel assembly with nodes at the two frame locations. ${ }^{7}$ The MIMO controller reduced the radiated sound power of the dominant $180 \mathrm{~Hz}$ mode by $9 \mathrm{~dB}$ and provided a total integrated reduction, from $150-800 \mathrm{~Hz}$, of over $4 \mathrm{~dB}$. The SISO controller did not perform as well, reducing the $180 \mathrm{~Hz}$ mode by only $4 \mathrm{~dB}$, and an integrated reduction of $2.55 \mathrm{~dB}$. There was some controller spillover from $350-500 \mathrm{~Hz}$ for the SISO control case. The performance of the SISO controllers was dictated by stability concerns. As the control effort penalty, $\lambda$, shown in equation 1 , was reduced to obtain good sound power reduction, the feedback controllers went unstable when all 6 loops were closed. The stability limit was probably related to cross coupling between bays. If all of the 6 bays were truly uncoupled systems then the performance of the MIMO and SISO control systems should be identical.

\section{Inter-bay Coupling}

Previous work on a similar panel system demonstrated significant noise reduction performance when two neighboring bays were controlled with independent SISO controllers. ${ }^{6}$ In those experiments, both fully coupled and independent controllers obtained broadband reductions of $9 \mathrm{~dB}$ over a bandwidth of 150 - $800 \mathrm{~Hz}$. It was hoped that the independent control scheme could be expanded to 6 bays without limitations created by cross coupling between the bays. However, the preceding results demonstrated the difficulty in expanding the SISO control system to 6 bays on this test panel. The cross coupling is quantified by the transfer functions between the bays. For example, the accelerometer responses on bay 1 due to an actuator input on bay 1 can be compared with the responses due to actuator inputs on the other bays. The 


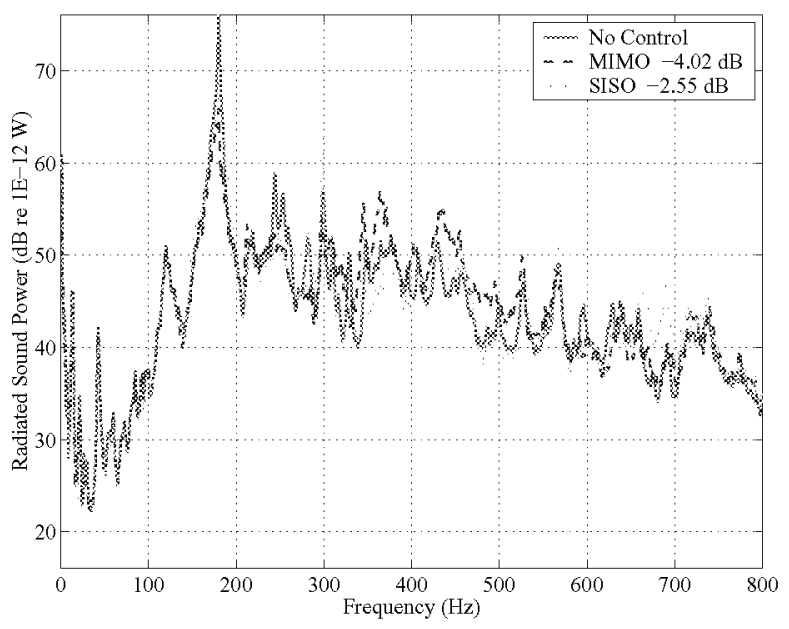

Fig. 4 Six Bay Control Results

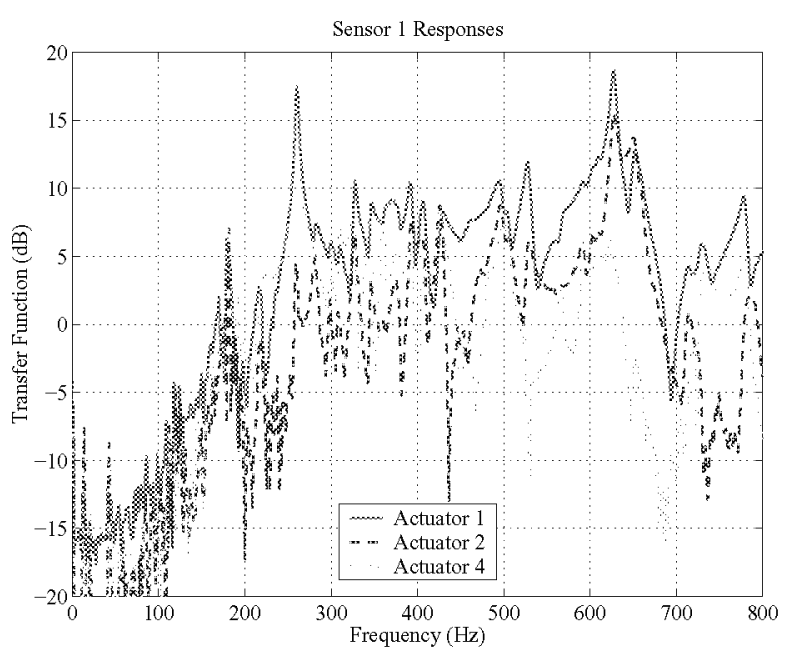

Fig. 5 Cross Coupling, Bay 1

cross coupling between neighboring bays 1,2 , and 4 is examined in more detail here.

The response of the control sensors on bay 1 , normalized to the excitation applied to actuators on bays 1,2 , and 4 is shown in Figure 5 . As shown in the figure the response of the sensors on bay 1 to an actuator input on that bay is highest across most of the frequency bandwidth. If bays 2 and 4 were decoupled from bay 1 their response curves would be significantly lower. It can be seen in the figure that both bay 2 and bay 4 have appreciable coupling across most of the bandwidth. The response due to bay 4 is higher than bay 2 for frequencies between $100-375 \mathrm{~Hz}, 750-950 \mathrm{~Hz}$. The response due to bay 2 is higher than bay 4 for frequencies between $450-700 \mathrm{~Hz}$.

The response of the sensors mounted on bay 2 , normalized to excitation on bays 1 and 2 is shown in Figure 6. It can be seen that the response due to Actuator 2 is larger over essentially the entire bandwidth; however, the response due to Actuator 1 is comparable

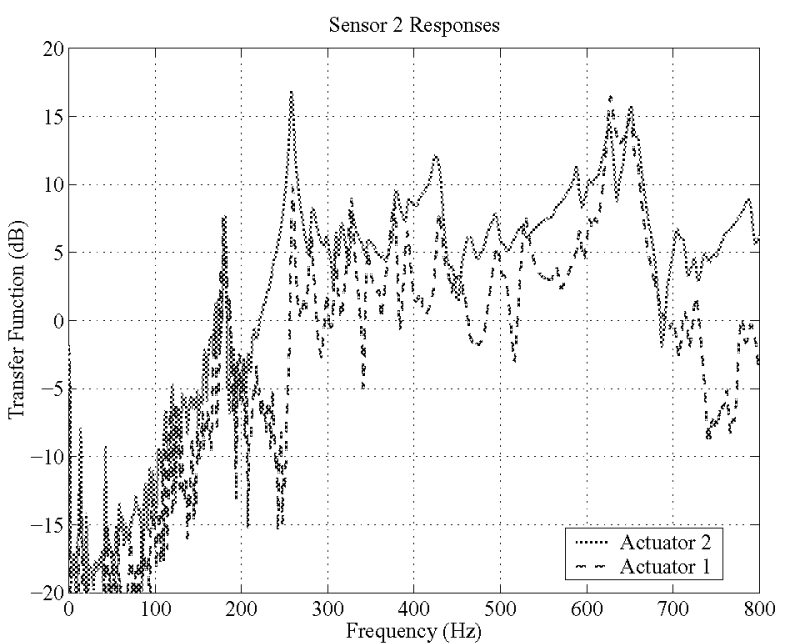

Fig. 6 Cross Coupling, Bay 2

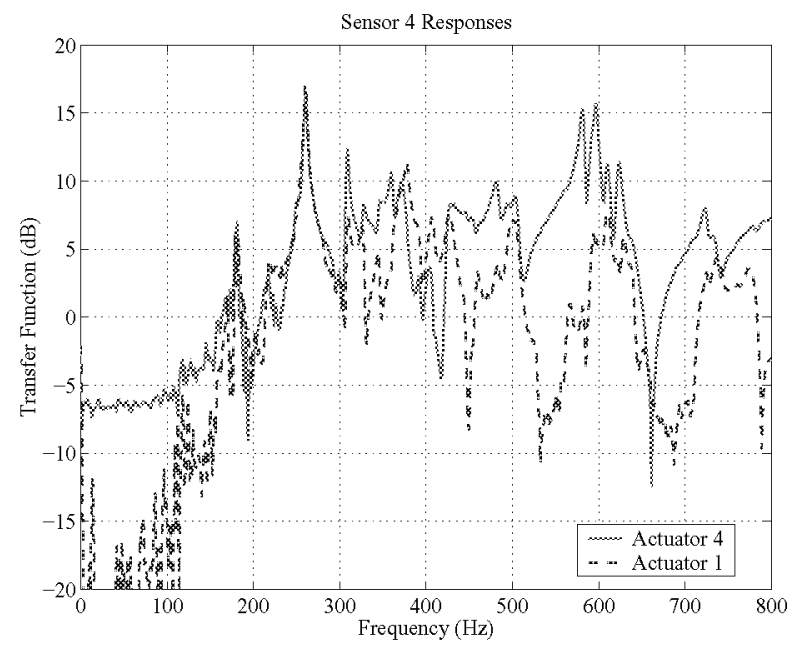

Fig. 7 Cross Coupling, Bay 4

to the response from Actuator 2 near the resonances of $180 \mathrm{~Hz}, 340 \mathrm{~Hz}, 625 \mathrm{~Hz}$, and $655 \mathrm{~Hz}$. By comparision, the response of sensors on bay 4 normalized to excitation on bays 1 and 4 is shown in Figure 7. The response of bay 4 to Actuator 1 is very strong over frequency bands of $210-325 \mathrm{~Hz}$ (exceeding the Actuator 4 curve from $225-250 \mathrm{~Hz}$ ), and $625-700 \mathrm{~Hz}$.

\section{Two Bay Adaptive Control}

In this section results of several two bay control cases will be discussed. In order to examine the effects of cross coupling, active control of two bays simultaneously was performed on bays 1 and 2 and then on bays 1 and 4 . Three control schemes will be demonstrated on these bays. First, a 2 input/output (2I2O) control system is evaluated and the control effort penalty adjusted for maximize reduction. Second, two independent SISO controllers are implemented and again the control effort penalty is adjusted such that maximum reduction is achieved. Third, two adaptive SISO controllers are implemented on two bays. 


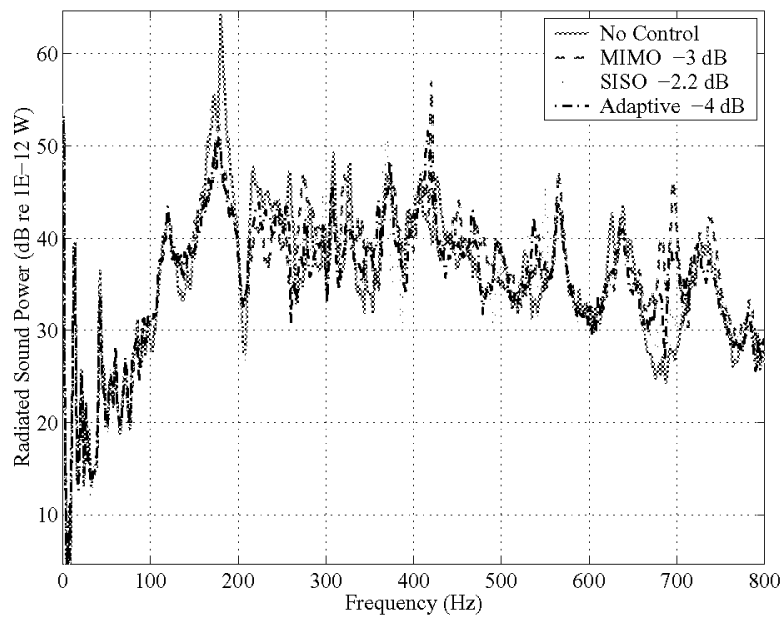

Fig. 8 Simultaneous Control of Bays 1 and 2, Bay 1 Radiation

Adaptive Control of Bays 1 and 2 Simultaneously

The two-bay adaptive control procedure was utilized for bays 1 and 2 on the panel. The radiated sound power results of the three active control experiments are shown in Figures 8 and 9 for bays 1 and 2, respectively. For bay 1 the MIMO controller reduced the radiated sound power by almost $10 \mathrm{~dB}$ at the 180 $\mathrm{Hz}$ mode and $3 \mathrm{~dB}$ integrated over a bandwidth of $150-800 \mathrm{~Hz}$. The independent SISO control system provided reductions of just over $2 \mathrm{~dB}$ integrated over the same bandwidth. The adaptive SISO control system demonstrated a reduction of $10 \mathrm{~dB}$ for the 180 $\mathrm{Hz}$ mode and $4 \mathrm{~dB}$ integrated over the bandwidth. Better performance can be seen for bay 2 where the MIMO controller provided $5.4 \mathrm{~dB}$ of reduction over the bandwidth of $150-800 \mathrm{~Hz}$, and the independent SISO controller provided $3.1 \mathrm{~dB}$ of reduction. The best performance was achieved with the adaptive SISO controller which provided a reduction of the $180 \mathrm{~Hz}$ mode of $15 \mathrm{~dB}$ and an integrated reduction of $7.5 \mathrm{~dB}$. Surprisingly the adaptive system provided more reduction than the fully coupled MIMO control system. Some spillover is noted at around $425 \mathrm{~Hz}$ and $700 \mathrm{~Hz}$ for the MIMO control system. The spillover can be reduced by increasing the control effort penalty and resulting in a subsequent loss in performance at $180 \mathrm{~Hz}$. The spillover can also be reduced by the addition of degrees of freedom in the system identification and controller.

\section{Adaptive Control of Bays 1 and 4 Simultaneously}

In this section the results of simultaneous active control of bays 1 and 4 will be presented. The total radiated sound power results for the three control cases are presented in the Figures 10 and 11 for bays 1 and 4 , respectively. The overall level of performance is below that presented in the previous section for bays 1 and 2. The MIMO control system reduced the radi-

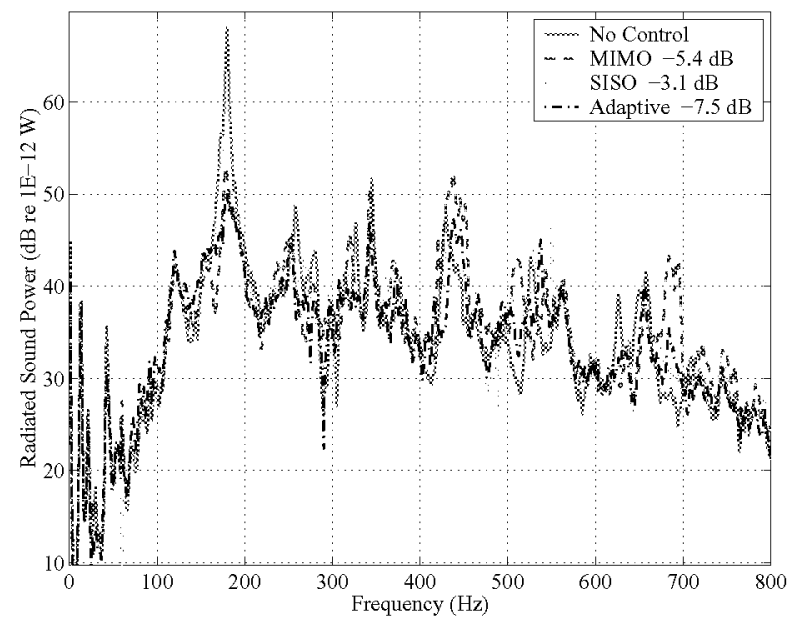

Fig. 9 Simultaneous Control of Bays 1 and 2, Bay 2 Radiation

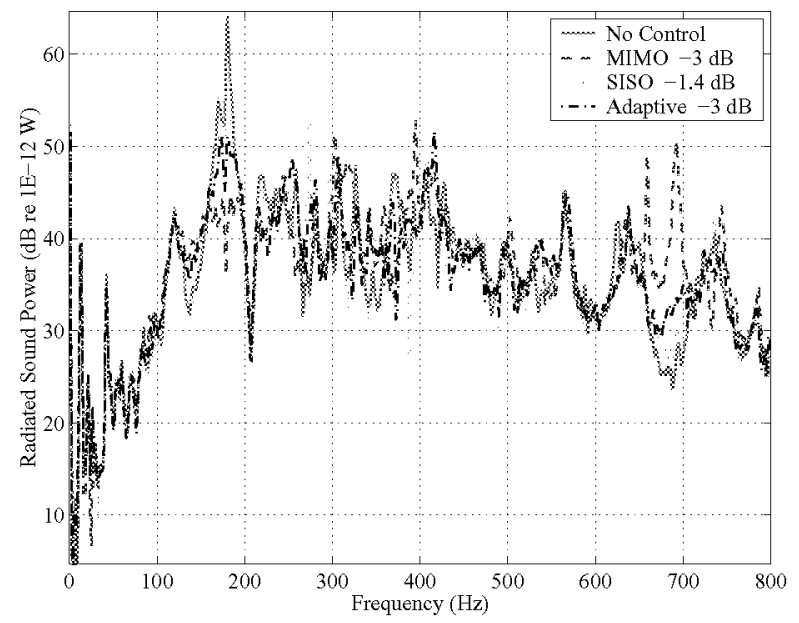

Fig. 10 Simultaneous Control of Bays 1 and 4, Bay 1 Radiation

ated sound power integrated over the bandwidth by 3 $\mathrm{dB}$ for bay 1 and $2.7 \mathrm{~dB}$ for bay 4 . The independent SISO control system only demonstrated reductions of $1.4 \mathrm{~dB}$ on each bay, and the adaptive SISO control system demonstrated reductions of $3 \mathrm{~dB}$ for bay 1 and 1.8 $\mathrm{dB}$ for bay 4 . In this case the adaptive control system performed better than the SISO system, but not quite as well as the fully coupled MIMO system.

Typically the control design using GPC is robust to small changes in the control effort penalty. As the control effort penalty is reduced with each subsequent control design the performance increases. At some point a minimum radiated sound power (maximum performance) is achieved. As the control effort penalty is further reduced spillover will occur driving up the radiated sound power from the minimum level; however, stability is still maintained. When the independent SISO controller was designed and imple- 


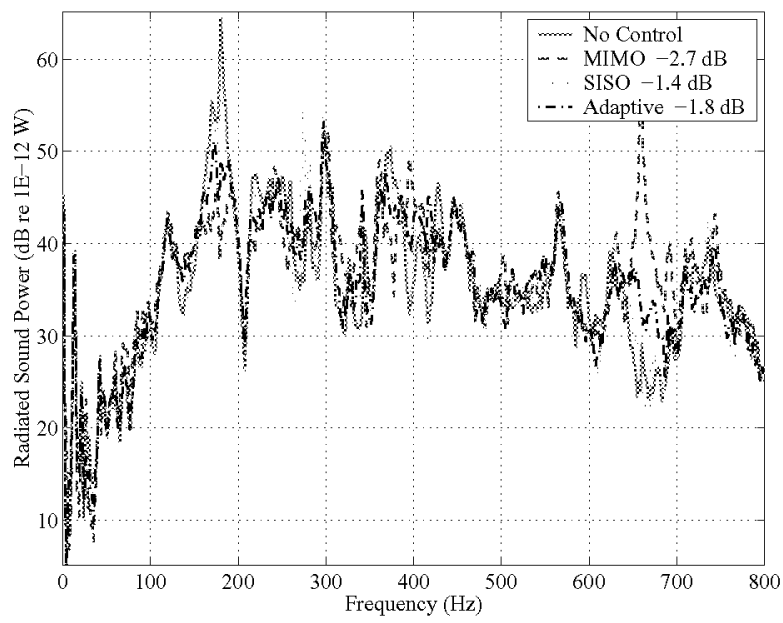

Fig. 11 Simultaneous Control of Bays 1 and 4, Bay 4 Radiation

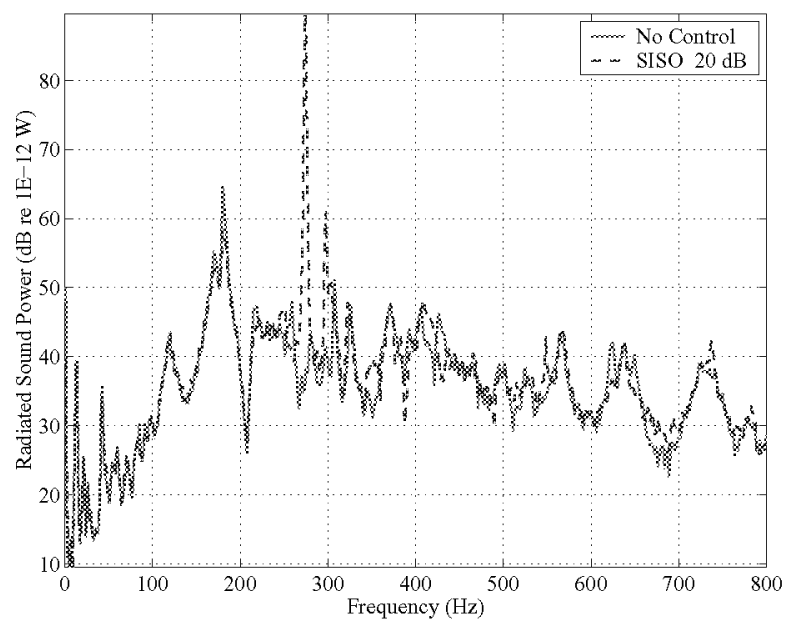

Fig. 12 Simultaneous Control of Bays 1 and 4, Bay 1 Radiation with Spillover

mented for bays 1 and 4 the system did not exhibit this behavior. The two distinguishing factors when comparing the MIMO and SISO cases were: The maximum reduction of sound power was significantly worse with SISO control, and further reductions in effort penalty below the optimal point resulted in marginally stable or unstable control designs. An example of a marginally stable control design is shown in Figures 12 and 13 . Note the extreme spillover at $275 \mathrm{~Hz}$ and $300 \mathrm{~Hz}$ resulting in a radiated sound power increase of $20 \mathrm{~dB}$. The frequencies demonstrating significant spillover also correspond to frequencies where the cross coupling is high between bays 1 and 4 as shown in Figures 5 and 7 . Future work will investigate metrics for determining the nature and severity of cross coupling, and the implication on control design and closed loop performance of multiple SISO control systems.

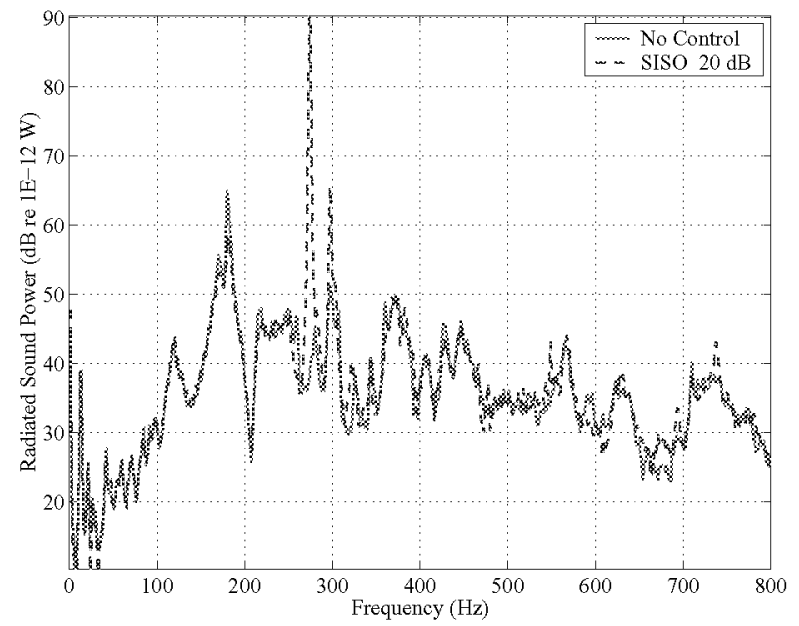

Fig. 13 Simultaneous Control of Bays 1 and 4, Bay 4 Radiation with Spillover

\section{Conclusions}

In this paper simultaneous active control of sound radiation from multiple panels subjected to turbulent boundary layer excitation was demonstrated. Three different control schemes were implemented: a single control system handling all bays simultaneously (MTMO), individual controllers acting on each bay (SISO), and individual controllers with adaptive ID and control design. The results demonstrate reductions in radiated sound power of up to $15 \mathrm{~dB}$ at the dominant $180 \mathrm{~Hz}$ resonance and up to $7.5 \mathrm{~dB}$ integrated over the bandwidth of $150-800 \mathrm{~Hz}$ at a flow speed of Mach 0.125. The results presented in this paper are the first known demonstration of active control of TBL excited broadband radiation from more than two bays simulaneously. Results from this experiment demonstrate the feasibility of reducing broadband radiation from multiple bays utilizing a single SISO controller per bay; however, cross coupling between bays may limit performance. A new fully adaptive control scheme provides additional performance and stability enhancements over an independent SISO control scheme.

\section{References}

${ }^{1}$ Thomas, D. and Nelson, P., "Feedback Control of Sound Radiation from a plate excited by a turbulent boundary layer," Journal of the Acoustical Society of America, Vol. 98, No. 5, Nov. 1995, pp. 2651-2662.

${ }^{2}$ Heatwole, C. M., Franchek, M. A., and Bernhard, R. J., "Robust feedback control of flow-induced structural radiation of sound," Journal of the Acoustical Society of America, Vol. 102, No. 2, Aug. 1997, pp. 989-997.

${ }^{3}$ Maury, C., Gardonio, P., and Elliott, S., "Active Control of the Flow-Induced Noise Transmitted Through a Panel," 6th AIAA/CEAS Aeroacoustics Conference, No. AIAA 2000-2042, Lahaina, Hawaii, June 12-14 2000.

${ }^{4}$ Augereau, P., "Feedback Control of the Sound Inwardly Radiated by an Aircraft Panel Excited by a Turbulent Boundary Layer," ISVR Technical Memorandum No. 869, Aug. 2001, pp. 1-48. 
${ }^{5}$ Froit, E. and Georgelin, M., "Real-time Control of a Vibrating Plate Excited by a Turbulent Boundary Layer," 137th Meeting of the Acoustical Society of America, Berlin, Germany, February 10-13 1999.

${ }^{6}$ Gibbs, G. P., Eure, K. W., and Lloyd, J. W., "Active Control of Turbulent Boundary Layer Induced Sound Radiation from Aircraft Style Panels," Proceedings of Active-99, Ft. Lauderdale, Florida, Dec. 1999.

${ }^{7}$ Gibbs, G., Cabell, R., and Juang, J., "Controller Complexity for Active Control of TBL Induced Sound Radiation from Panels," 6th AIAA/CEAS Aeroacoustics Conference, No. AIAA 2000-2043, Lahaina, Hawaii, June 12-14 2000.

${ }^{8}$ Gibbs, G. P., Clark, R. L., Cox, D. E., and Vipperman, J. S., "Radiation modal expansion: Application to active structural acoustic control," Journal of the Acoustical Society of America, Vol. 107, No. 1, Jan. 2000, pp. 332-339.

${ }^{9}$ Clarke, D., Mohtadi, C., and Tuffs, P., "Generalized Predictive Control - Part I. The Basic Algorithm," Automatica, Vol. 23, No. 2, 1987, pp. 137-148.

${ }^{10}$ Anderson, B. and Moore, J., Optimal Control - Linear Quadratic Methods, Information and System Sciences Series, Prentice Hall, Englewood Cliffs, New Jersey, 1990.

${ }^{11}$ Garcia, C. E., Prett, D. M., and Morari, M., "Model Predictive Control: Theory and Practice - a Survey," Automatica, Vol. 25, No. 3, 1989, pp. 335-348.

${ }^{12}$ Mosca, E., Optimal, Predictive, and Adaptive Control, Prentice Hall, 1995.

${ }^{13}$ Skogestad, S. and Postlethwaite, I., Multivariable Feedback Control: Analysis and Design, John Wiley \& Sons, West Sussex, England, 1996. 